\title{
Coronavirus Disease 2019: Why Some Countries Appear to be Relatively Spared
}

\author{
Ahmed J. Aldeeb \\ Doha College, Al Mansoura, Doha, Doha, PO Box 7506 , QATAR; ahmedjehaddev@gmail.com
}

ABSTRACT: The COVID-19 pandemic has affected numerous countries worldwide, however some countries appear relatively spared when compared to others. There are countless factors affecting the spread of the virus and its distribution. This study aimed to characterize factors such as: population density, age of the population, climate \& immunology, and strategies/measures used by nations to combat the spread of the virus. Whilst these factors play substantial roles in explaining the possible reasons for the uneven distribution around the world, there were a few exceptions to each of the findings. Furthermore, precautionary measures and effective strategies to limit and combat the spread of COVID-19 have played a significant role regardless of factors such as regional climates, population density, and more. Above all, it is important to note that with additional knowledge and information about the virus, scientists and researchers will be able to develop more effective approaches in responding to such a virus, and even future diseases.

KEYWORDS: Biology; COVID-19; population age; climate; Immunology; population density; inflammation; medicine.

\section{Introduction}

COVID-19 was first identified on 31 December 2019, following a report of a cluster of cases of "viral pneumonia" in Wuhan, People's Republic of China. The World Health Organization proclaimed the outbreak a "Public Health Emergency of International Concern" in January 2020, and in March 2020 declared it a pandemic. As of the 19th of December 2020, 5:22 pm CET, there have been 74,299,042 \pm total cases globally; with the Americas accounting for about $43 \%$ of the cases (globally), and Europe accounting for about $32 \%$ of the total cases (globally), while the Eastern Mediterranean, Africa, South East Asia, and the Western Pacific regions combined account for just around $25 \%$ percent, despite housing around $6,283,110,834 \pm$ people which is about 4 times more compared to the Americas' and Europe's population of $1550260479 \pm$. In this report (Figure 1), ${ }^{1,2}$ the reasons behind this significant difference will be investigated and specific countries will be explored further to thoroughly understand and examine examples of how some factors might come into play.

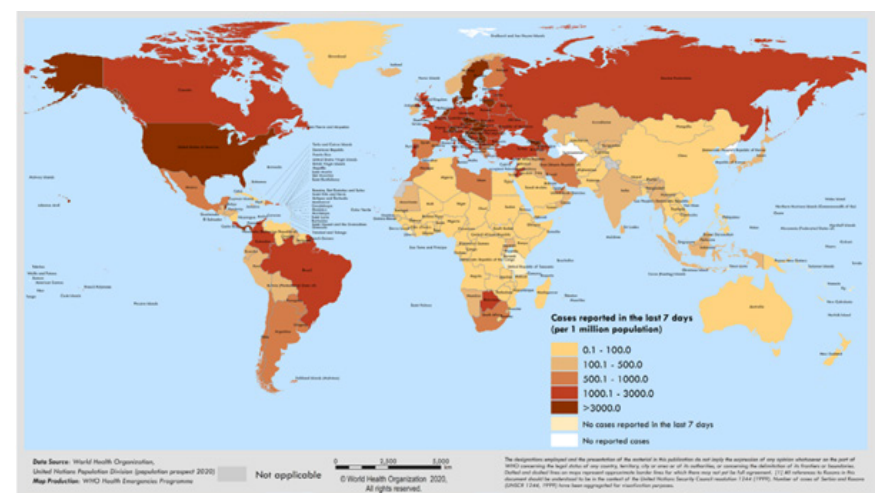

Figure 1: Map displaying total cases reported (per 1 million population) in the last 7 days, as of 2020/12/19, 5:22 pm CET. ${ }^{1}$
Based on the data, the Americas had the most cases, 31,925,704, and following that Europe, with 23,457,397 cases, Southeast Asia, 11,572,247, Eastern Mediterranean at 4,641,968, Africa at 1,701,091, and finally the Western Pacific region at 999,891 . However, what is unusual is the great difference in population between the regions. For instance, the Americas account for 802,409,370 (approximately 10.2\%) of the global population (at the time of writing is $7,833,371,313){ }^{2}$ and Europe with 747,851,109 (approximately 9.5\%) of the population. In contrast, all of the other regions, in spite of having a population of $6,283,110,834 \pm$ (more than 4 times as much as the population of the Americas and Europe); report fewer cases compared to the Americas and Europe (Figure 2). This might be due to efficient practices and measures, political aspects, availability of healthcare, environmental aspects, and numerous other factors.

\section{Population Density:}

Population density is the number of individuals per unit geographic area, numerous politicians and public figures have argued that population density affects the transmission of the virus (Figure 3). ${ }^{3}$ However, it is one of many factors that affect the transmission rate of the $2019-\mathrm{nCoV}$, that should be taken into account while understanding the reasons behind this abnormal distribution of cases in different countries.

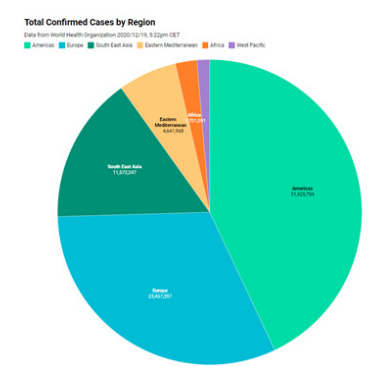

Figure 2: Pie chart displaying the total confirmed cases by region according to the World Health Organization. ${ }^{1}$ 


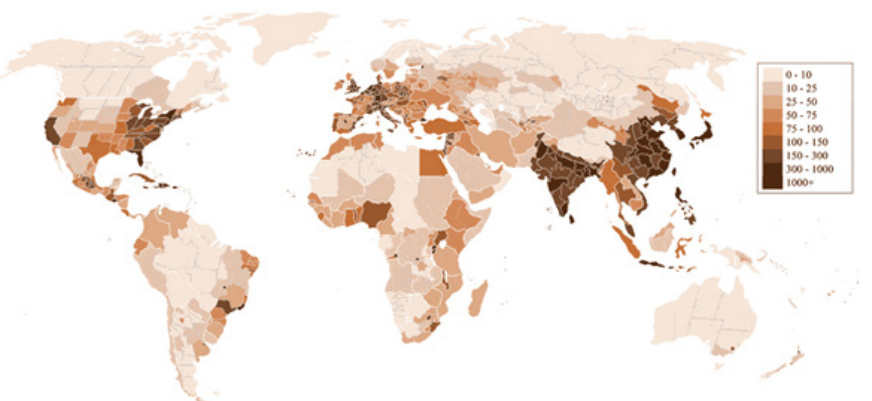

Figure 3: Map displaying population density of countries and states around the world according to the CIA World Factbook. ${ }^{4}$

According to the World Health Organization, Singapore, Hong Kong, Bahrain, Malta, Bangladesh, Palestine, Lebanon, Taiwan, South Korea, Rwanda (excluding island nations or territories, "read notice*) place the top ten most densely populated countries in the world. ${ }^{1}$

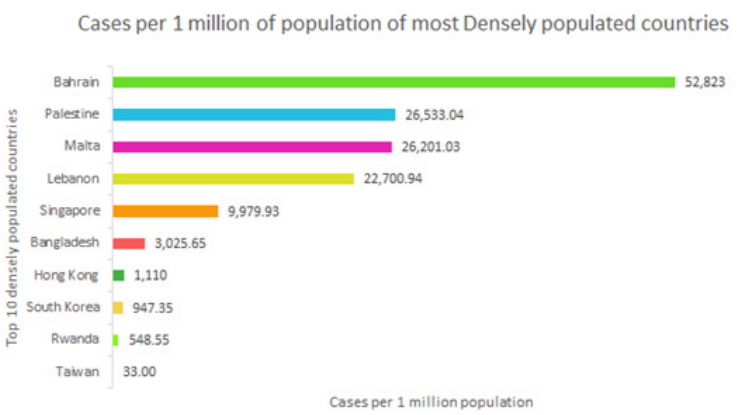

Figure 4: Graph displaying the total cases per 1 million population of most densely populated countries around the world..$^{1,4}$

As shown in Figure 4, the included countries all belong either to the Eastern Mediterranean, Southeast Asia, Africa, and Western Pacific regions (with the exception of Malta, an island country in the Mediterranean Sea and part of the EU politically, however geographically speaking part of Africa). It can also be seen that countries that are located in the Eastern Mediterranean account for more cases per 1 million population. However, it should be noted that the top 4 countries have a smaller population compared to the rest. For example, Bahrain has 1.569 million people, while Taiwan has 23.78 million people; so, if a number of cases appear, the cases per million population would be higher in Bahrain than in Taiwan. This method is more efficient and accurate in comparing countries rather than using the number of total cases, as every country has a different population. According to the data, it can be observed that countries like Rwanda, South Korea, Hong Kong, and Taiwan are responding exceptionally well to the COVID-19 pandemic.

Similarly, in less densely populated countries, it was observed that countries in the Americas, and Europe have the highest cases per 1 million population (with the exception of Libya, an eastern Mediterranean country). While countries like Australia, and Mongolia (Western Pacific) had fewer cases, with the African countries following (Figure 5).

As Mongolia, Australia, Suriname, Iceland, Guyana, Libya, Mauritania, Botswana, Canada, and Russia place the top ten least populated countries in the world respectively; we can clearly show that population density doesn't affect the cases per 1 million population, just like in the previous example (Figure 5).

Cases per 1 million of population of least Densely populated countries

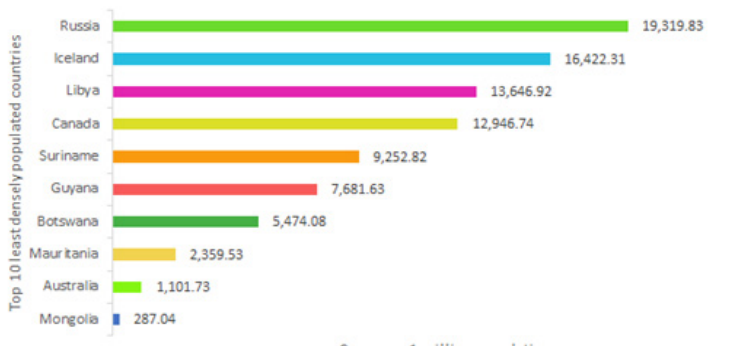

Cases per 1 million population

Figure 5: Graph displaying the total cases per 1 million population of least densely populated countries around the world. ${ }^{1,4}$

As a whole, despite being more densely populated, some countries like South Korea, Rwanda, Hong Kong, and Taiwan managed to have fewer cases per 1 million population than less densely populated countries. This shows that population density does not necessarily play a role in a country's cases. Furthermore, the Americas, Europe, and some Eastern-Mediterranean countries performed worse than Western-Pacific, and African countries.

\section{Young Population:}

Additionally, aging might be a contributing factor in the uneven distribution of cases around the globe (Figure 6).

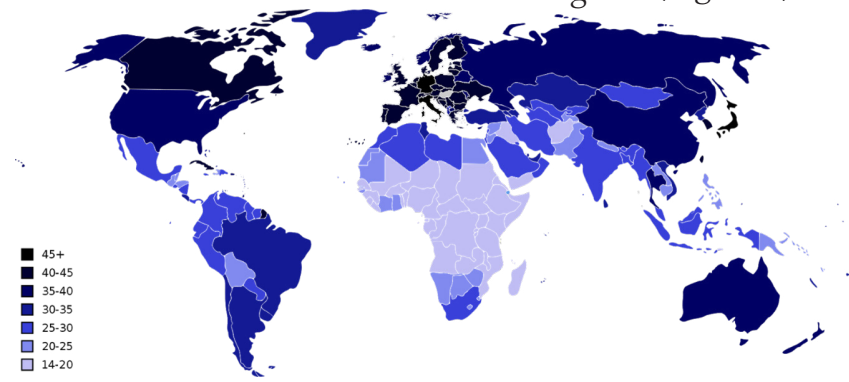

Figure 6: Map displaying Median age by country, according to CIA World Factbook 2018 est.

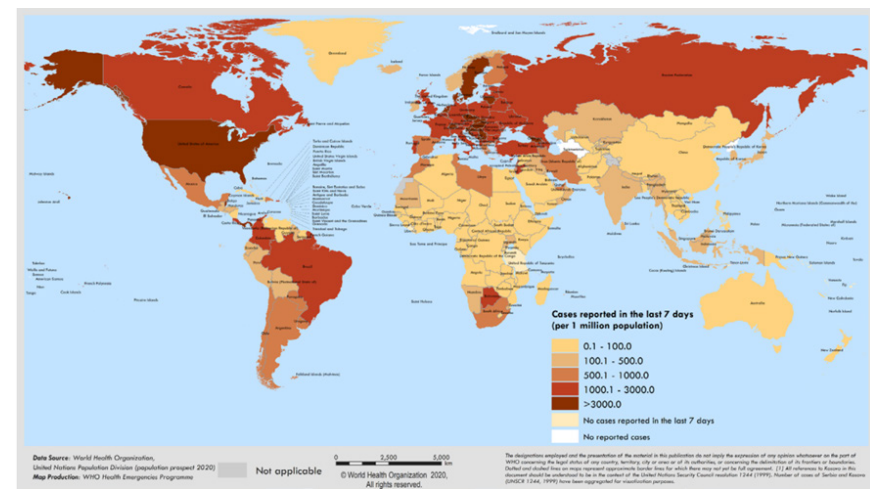

Figure 7: Map displaying total cases reported (per 1 million population) in the last 7 days, as of 2020/12/19, 5:22pm CET.

Comparing Figures 6 and 7, it can be clearly seen that there is a moderate relation between the median age of countries and the reported cases in the last 7 days, from the time of this writing. There are some outliers, such; as Australia, New Zealand, China, Ireland, etc., however in the majority of countries, a pattern can be noticed, the older the population, 
the more cases, and the younger the population, the fewer the cases.

In addition, African, Eastern Mediterranean, Western Pacific, and South-East Asian regions appear to be relatively spared compared to the Americas and Europe.

To further investigate the matter, I decided to take the newly reported cases in the last seven days from the top 10 countries with the youngest and oldest populations (according to CIA World Factbook 2018 estimate), ${ }^{4}$ and compare them with each other and point out the differences and similarities between the cases and age, and the possible causes.

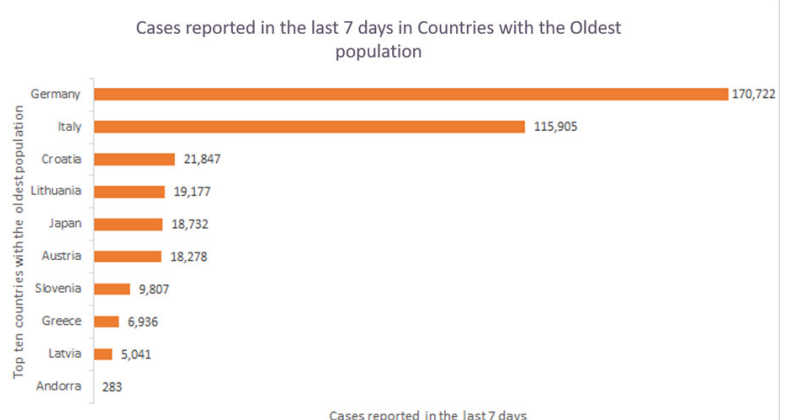

Cases reported in the last 7 days

Figure 8: Graph representing the cases reported in the last 7 days in countries with the oldest population.

Based on Figure 8, all of the countries, except Japan, are in Europe, and Western Europe seems to be more affected than Eastern Europe and the Balkans. The country that was most affected was Germany, with 170,722 cases reported in the last 7 days. While the least affected country Andorra, which only has a population of $76,177 \pm$ people, reported 283 cases in the last 7 days.

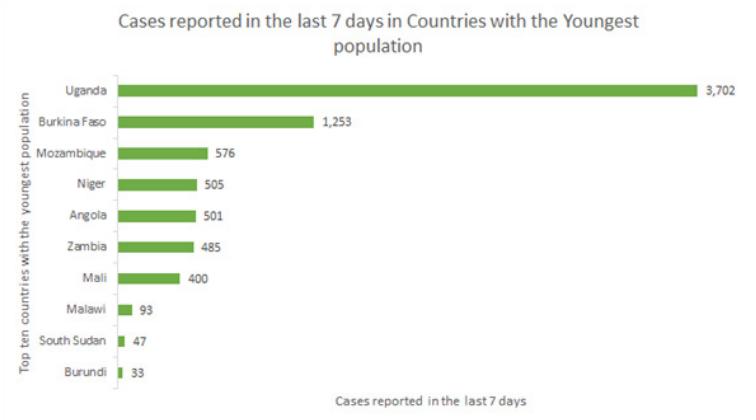

Figure 9: Graph representing the cases reported in the last 7 days in countries with the oldest populatios.

Based on Figure 9, all of the 10 countries are from Africa, which does explain why they are spared more when compared to other regions. The country with the highest number of cases reported in the last 7 days was Uganda, with 3,702 cases reported in the last 7 days, while Burundi accounted for the least number of cases (in the last 7 days), for a total of 33 .

The difference can be clearly observed, which confirms that the age of a country's population does affect the case count to varying degrees and does not apply in all circumstances. In addition, Uganda, with 3,702 cases, accounts for fewer cases reported (in the last 7 days) than the top ten countries with the oldest populations (with the exception of Andorra) in the world. From the data, Africa's young population has clearly helped it to accumulate fewer cases. The same can also be said for most of Asia. This is clearly the result of declining mortality, and the high fertility rate amongst people, especially in Africa. ${ }^{6}$ Despite the information gathered, the reasons behind the probability of catching the virus in varying ages needs to be explained thoroughly, as a lack of available information regarding the probability of different age groups catching the virus, is present.

Although there have been several studies on this matter, the research records the number of cases reported from each age group, as seen below (Figure 10) from the Georgia Department of Public Health, and not the immunity of different ages catching the virus. ${ }^{7}$

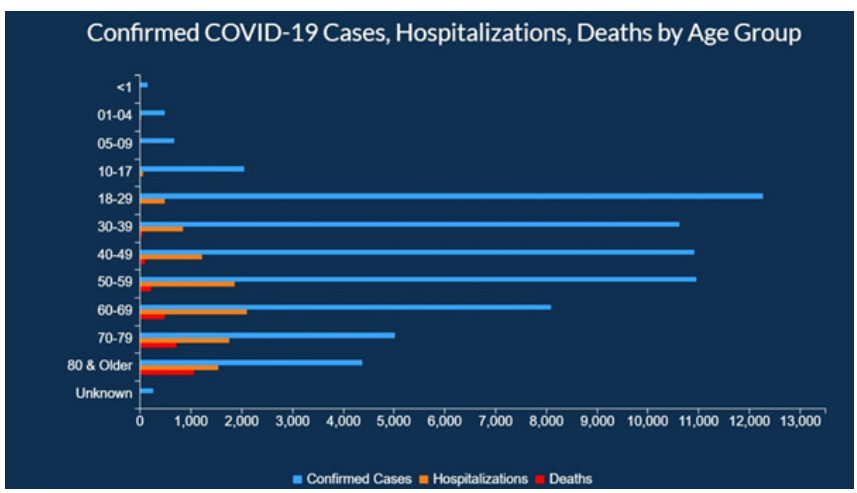

Figure 10: Graph representing and comparing the cases, hospitalizations, and deaths by age groups, according to the Georgia Department of Public Health. $^{7}$

What is not ideal in this method is that it is obvious that people of ages, $18-59$, spend more time outside, ${ }^{8}$ than children, teenagers, and the elderly. This of course varies but is true for the majority of people. Therefore, this does not measure the immunity towards the virus, but instead the age groups and their cases and deaths. ${ }^{9}$

Nonetheless, the difference between the younger and older populations is believed to be a result of the aging immune system. However, information about this has not been thoroughly explored as minimal research has been done in this area.

\section{Aging Immune System:}

An aging immune system may have an effect on the probability of catching a virus and responding to it. The immune system protects the body from external and internal stressors (harmful substances, germs, and cell changes that could make a person ill). ${ }^{10}$ It is beneficial for fighting pathogens like bacteria, viruses, parasites, or fungi, as well as for recognizing and neutralizing harmful substances from the environment. In addition, the immune system is responsible for fighting off disease-causing changes in the body, such as cancer cells or in this case COVID-19 infected cells.

As people age, the immune system changes in several ways. Immunosenescence, the aging process that leads to dysregulation of immunity and a person's adaptive response to pathogen exposure, is one major factor in the changes the immune system goes through in the process of aging. Another noteworthy process is Inflammaging, which is a chronic increase in systemic inflammation, that attacks mainly the macrophage as one of its major target cells in this process. ${ }^{11}$ 


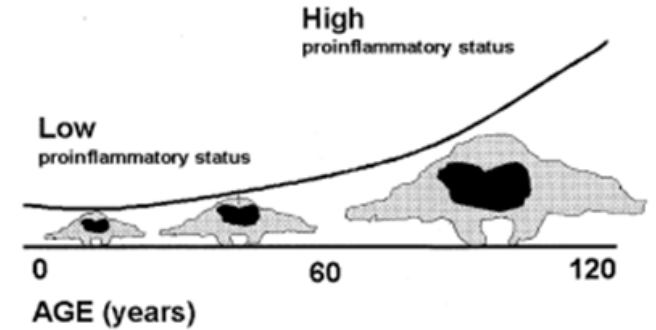

Figure 11: Inflamm-aging as a consequence of macroph-aging. ${ }^{11}$

As seen above (Figure 11), this prediction conveys a relation between age and macrophage activation, which is mostly responsible for the presence of a subclinical chronic inflammatory process in the elderly. Though, macrophages are not the only cell involved in this process, as cells like lymphocytes are also affected by immunosenescence.

As a whole, immunosenescence, and inflammaging affect the immune system during aging. This could be a factor attributed to the distribution of cases throughout countries depending on ages.

\section{Climate and immunolog:}

Climate and Immunology can be a noteworthy consideration for the spread of the coronavirus among countries.

A coronavirus is a single-stranded RNA-enveloped virus. Non-enveloped viruses -- such as coxsackieviruses, poliovirus, and rotavirus - cannot survive for extended periods of time on surfaces and can be affected by heat, moisture, or $\mathrm{pH}$. On the other hand, enveloped viruses (such as the coronavirus); can remain infectious on surfaces for several days. The persistence of viruses, for example the coronavirus, can be affected by environmental conditions and factors like heat, moisture, $\mathrm{pH}$, and the type of surface. ${ }^{12}$ Furthermore, conditions such as heat can be found in the principle behind inactivated vaccines; where viruses such as measles, mumps, and rubella are inactivated with heat or formaldehyde -- a notable example is the BBIBP-CorV vaccine from Sinopharm. ${ }^{13}$ Evidently, the virulence of coronaviruses (including SARS-CoV-2) appears to attenuate or get completely inactivated by heat; in our case the Tropical Sun.

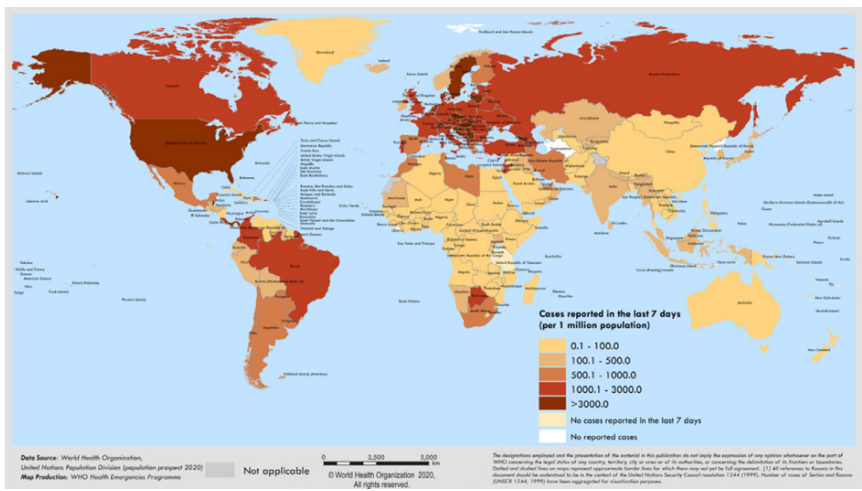

In the above image, it can be seen that the tropics, sub-Saharan, and Sahelian regions; spanning from Mauritania, Morocco, and the Western Sahara region to Egypt and eastern African countries, through the Middle East, and into SouthEast Asia, appear to be relatively spared. Other regions, such as the Malay Archipelago and the Western Pacific (Oceanic) regions also appear to be spared in mortality rates and cases (Figure 12).

As such, this evidence might also aid in the understanding of why certain regions appear to be spared in case count and mortality rates. Due to the nature of the virus being incapable of withstanding heat, the coronavirus would not be able to remain on surfaces as long compared to regions with relatively colder temperatures. This helps explain why there is a significant difference in cases between countries that are located in regions with hotter temperatures and countries with relatively colder temperatures.

\section{How countries are battling the spread of the virus:}

Various countries have implemented different strategies into battling the spread and effects of the virus. However, only a few countries have managed to conduct notable measures into limiting the development of the problem. One of many examples is Hong Kong, which has maintained a profoundly low numbers of cases and deaths, despite close proximity to China, and its reputation as a major transport and economic hub. Its sustainable measures and its fixed attitude amongst its people and culture (for instance, citizens wear masks to keep their faces warm in the winter and offer a sense of protection from air pollution, including any airborne germs prior to the pandemic) have helped the state to overcome any major problems that can be caused by the pandemic. ${ }^{14}$

\section{Hong Kong:}

Hong Kong is a country that imposes a great example of dealing with the coronavirus. This can be seen by the relatively low case count compared to many other countries, despite its remarkable status as an international transport hub. Evidently, this can be attributed to several implementations and procedures the government imposed on its population.

To begin with, experts believe the habit of wearing masks in public since the 2003 SARS epidemic has helped keep the number of cases relatively low. Additionally, border restrictions, quarantine and isolation, social distancing, and behavioral changes (such as wearing masks) may have had a role in containing the spread of the virus. ${ }^{15}$

Subsequently, during the 4th wave, schools were suspended until further notice, and businesses' working hours were reduced; to further reduce the spread. In addition to this, a mandate for authorities to order partial lockdowns on locations with multiple cases of COVID-19 until all residents were tested. ${ }^{16}$

From late January 2021, the government repeatedly locked down residential buildings to conduct mass testing. Steps have also been taken to limit the spread and death count by vaccination, as a free mass vaccination program has been launched from the 26th of February. ${ }^{16}$

There are numerous other examples of countries that have been able to contain the spread of the virus, in similar strategies to that of Hong Kong-- like Taiwan, South Korea, and more -- which also demonstrated outstanding results after implementation. ${ }^{17}$

\section{Vacciness:}

This paper has explored how inactivated vaccines may be able to protect against infection through exposure to heat. It 
is important to note, that vaccine pioneers can also inactivate a version of a virus through radiation and chemicals, or by containing a similar virus that resembles the real one. ${ }^{18}$ This is seen in vaccines offered by Sinovac, Bharat Biotech, and Sinopharm. ${ }^{18}$ However, there are numerous other types of vaccines, such as RNA, Viral Vector Vaccines, and Protein subunit vaccines. RNA vaccines work by the concept of messenger RNA, which is a sequence of genetic code that communicates with our cells to ensure the necessary proteins are built. ${ }^{19} \mathrm{In}$ such vaccines, scientists develop a synthetic version of the virus' messenger RNA. When injected into the body, cells read the instructions and start building the necessary viral proteins; prompting the immune system to respond so it can learn to protect itself against future COVID-19 infection. This technology is used by Moderna and Pfizer-BioNTech, and have reported high levels of efficacy- around $95 \% .{ }^{20}$

\section{- Conclusion \\ Future directions:}

Above all, the coronavirus has affected the majority of countries around the world, with some nations being relatively more spared than others. However, many factors can affect the number of cases and deaths in countries. As discussed in this research paper; the population density of the country, the age of the population, immunology, climate, and precautionary measures could potentially help explain the reasons behind the disproportionate distribution of cases among countries in the world. Factors such as the coronavirus' persistence based on temperature, can help aid in the understanding of how it might react and can help develop an understanding of the virus. These factors therefore potentially allow the production of inactivated vaccines with the help of heat or formaldehyde. Additionally, precautionary measures taken by countries around the world can be used as an influential example for other countries and people to implement. Nevertheless, some factors cannot be changed such as the age of the population and the population density of a country. However, this can help us to study and comprehend how individuals and age groups are affected, as well as the environments people live in. The foregoing factors that were included in this paper are only a few of many reasons and factors that affect the spread and mortality rate of the virus. Despite this, more information and relating factors would be able to provide additional details and information to assist in the understanding of a phenomenon such as COVID-19. For the foreseeable future, more information would assist in the development of cures, vaccines, and precautionary measures and help prevent a phenomenon similar to this from occurring again.

\section{- References}

1. https://drive.google.com/file/d/1cqd6uZMmj4G09RgqZZogQ W11wOJNd0c6/view? usp=sharing

2. https://www.worldometers.info/world-population/2020/12/ 19,5:22pm CET

3. https://www.medrxiv.org/content/10.1101/2020.10.16.2021389 $2 \mathrm{v} 2$.full

4. https://www.cia.gov/library/publications/resources/the-world -factbook/fields/343rank.html

5.https://en.wikipedia.org/wiki/List_of_countries_by_median_age 6. https://qz.com/africa/1099546/population-growth-africans-will -be-a-third-of-all-people-on-earth-by-2100/

7. https://www.11alive.com/article/news/health/coronavirus /coronavirus-numbers/georgia-age-group-most-covid-19-cases -18-29/85-277d5702-25fa-4ff8-8b5e-7f803b925adc

8. https://e360.yale.edu/digest/u-s-study-shows-widening -disconnect-with-nature-and-potential-solutions

9. http://phmovement.or.kr/south-korean-kids-get-just-34-minutes -of-outside-play-time-a-dayhankyoreh/

10.https://www.ncbi.nlm.nih.gov/books/NBK279364

11.https://d1wqtxts1xzle7.cloudfront. net/49787813/j.1749-6632.2000.tb06651.x20161022-142791s1v7mo-with-cover-page-v2.pdf?Expires=1640930139\&S ignature=AR0ZsHEIbt24PcbXekDKX4GVuF5ihdw9K9GOw Mx01at7IRgDf3KxSektJA5POFKMpEMqoXPeWjs0GoUao4C4psIvDPlgRLcNtAVujdIVTcvFL5AWt0EKUO1 BxknIgCqP YXUm1aqyYum4eAxdFauCnF5808wZIOYM2Y8qCy2oqY5uR Ky8N6wNCZSBSy7iGrcgSWAoIRk9G710v31Pw4x-n-mUziDH7cGKvdx-zL6w6YQPECLNxkAdFh2iIs3p4p1NCOKJaf WYnutKDigsrBCtjPY6Qr tzppW6kYJ y8QsXOmrbgsjz3P Wd4zEXmlWsnLA9gxmQUKEYmoUtltBIA_\&Key-PairId=APKAJLOHF5GGSLRBV4ZAi

12.https://www.jstage.jst.go.jp/article/jsme2/30/2/30_ME14145/ _pdf/-char/en

13.https://www.medicalnewstoday.com/articles/covid-19-howdo-inactivated-vaccines-work\#Making-inactivated-vaccines

14.https://www.voanews.com/science-health/coronavirus-outbreak/ not-just-coronavirus-asians-have-worn-face-masks-decades

15./https://www.scmp.com/news/hong-kong/health-environment/ article/3078437/mask-or-not-mask-who-makes-u-turn-while-us

16.https://hongkongfp.com/2020/12/08/hong-kong-plans-partiallockdowns-for-covid-19-hotpots-and-more-tests-as-number-ofnew-infections-surges/.

17.https://healthmanagement.org/c/hospital/news/where-are-themost-effective-anti-covid-19-strategies

18.https://www.thelancet.com/article/S1473-3099\%2820\%29308434/fulltext

19.https://www.cdc.gov/coronavirus/2019-ncov/vaccines/differentvaccines/mrna.html\#: :text=mRNA\%20vaccines\%20teach $\% 20$ our\%20cells,getting\%20sick\%20with\%20COVID\%2D19.

20.https://pubmed.ncbi.nlm.nih.gov/33629336/

\section{- Author}

Ahmed Aldeeb is a 13-year-old student who is interested in researching COVID-19 and its effects on a global magnitude, and the creator of the coronavirus-tracking website www.coronaviruslive.io. 